\title{
The effect of temporal factors on the maintenance of discriminated avoidance
}

HARRY L. CHIPMAN, Jr. MARY WASHINGTON COLLEGE OF THE UNIVERSITY OF VIRGINIA

The DAWE procedure of Hurwitz has characteristics of both free-operant and discriminated avoidance paradigms. Hooded rats, after acquiring $D A W E$ were exposed to manipulations of the latter paradigm. These manipulations provided a constant response-shock interval, a controlling factor of free-operant avoidance. However, significant differences between treatments were found.

In response to reported difficulties in obtaining bar press avoidance with rats, Hurwitz (1964) described a new procedure. This procedure incorporated the fixed-cycle avoidance of Sidman with an exteroceptive signal as a conditioned stimulus. This procedure differs from the discontfnuous shock paradigm described by D'Amato, Keller, \& Di Cara (1964).

Ferster \& Skinner (1957) have compiled research on the parameters controlling operant behaviors. These studies did not make use of noxious stimuli. It would be desirable to have comparable information on the maintenance of discriminated avoidance without escape (DAWE) behavior. However, the parameters of this procedure have not been completely defined. Studies of discrimination avoidance paradigms suggest that important parameters are the intertrial and interstimulus intervals. Research on the free operant avoidance paradigm (Sidman, 1966) has shown that the responseshock interval can control bar press avoidance behavior. The response-shock interval would be equivalent to the sum of the intertrial and interstimulus intervals in discriminated avoidance.

As indicated above, the DAWE procedure appears to be a hybrid of the free operant avoidance and discriminated avoidance paradigms. Would manipulations of the latter produce a significant effect even though a controlling factor of the former was held constant? This report attempts to answer this question.

Subjects

Three adult male hooded rats of the Long-Evans strain were the Ss. They were maintained on ad lib conditions. Previously, each had served in an avoidance conditioning experiment using the Hurwitz procedure, and had attained $70 \%$ avoidance.

\section{Apparafus}

A commerclally avallable test chamber for rats (Scientific Prototype) with a PM speaker and a lever mounted in the same wall was used. The chamber's grid floor was wired for scrambled shock. The shock scrambler was constructed by the Purdue University Psychology Department shops. The test apparatus was housed in a sound attenuating cubicle which was equipped with a blower in the roof and a 7-1/2 W lamp on the rear wall at the top. The lamp was on continuously during testing.

The output of a click generator delivered to the PM speaker served as the conditioned stimulus (CS). The intensity of this rapid clicking sound was $56 \mathrm{~dB}$. All contingencies were controlled by automatic programming equipment housed in an adjacent room.

Design

Three treatment combinations were administered to each $S$ in a balanced order specified by a Latin square. These were combinations of intertrial intervals (ITI) and interstimuius intervals (ISI) in seconds: 5/15, $10 / 10$, and $15 / 5$. Each combination ytelds a responseshock interval of $20 \mathrm{sec}$. None of these combinations had been used previously.

Precedure

The procedure used was essentially that described by Hurwitz \& Dillow (1966). The following modifications were made: CS-auditory; shock duration, .2 sec and intensity, $1 \mathrm{~mA}$; and shock-shock interval, $15 \mathrm{sec}$. Shortly after placing $S$ in the test chamber the CS was presented and, unless a bar press was made during the ISI, the first of a series of shocks was delivered. A bar press terminated both the CS and the shock cycle. Following the ITI, the sequence was repeated. Each $S$ performed under its assigned treatment $2 h$ per day for four consecutive days. After one day off, the entire sequence was repeated for the next treatment.

The avoidance responses ( responses occurring during the ISI) for each treatment condition were converted to percent avoldance scores. Other measures have been suggested (Hurwitz \& Dillow, 1966); however, percent avoidance seems most appropriate for this experiment because it adjust for fluctuations in total number of responses. For the most part these fluctuations are a function of the experimental manipulations, as can be seen in the following example. Assuming perfect performance (100\% avoidance), the number of avoidance responses for one testing session for each treatment conditions (ITI/ISI) would vary: Treatment 15/5, 480; Treatment 10/10, 720; and Treatment 5/15, 1440. Results and Disenssien

The treatment percent avoldances are: Treatment 15/5, 61.7; Treatment 10/10, 70.3; and Treatment 5/15, 76.6. Differences between all pairs of the above were tested by standard procedures for percentages (Downie \& Heath, 1965). The results of all tests were significant beyond the .01 level. 
The DAWE procedure employs the fixed interval shock cycle of the free operant paradigm. Yet, the treatment differences reported here suggest that an important temporal factor of that paradigm, response-shock interval, does not control DAWE behavior. To be sure, this statement is subject to many of the limitations inherent in comparisons of discriminated avoldance with free operant avoidance. These limitations have been discussed by Hoffman (1966).

It might be argued that these differences were the result of some CS duration phenomenon, not of temporal factors. Pearl \& Edwards (1962) reported a relationship between the acquisition of a bar press avoidance (not DAWE) and CS duration. The apparent support provided by their findings is questionable, since it appears that ITI was uncontrolled.

As previously mentioned, the experimental treatments employed here allowed markedly different numbers of responses per session to be made. This factor might account for the treatment differences. Further experiments are planned to examine this explanation and the factors controlling DAWE behavior.

References

D'AMATO, M. R., KELLER, D., \& DI CARA, L. Facilitation of discriminated avoidance leaming by discontinuous shock. J. comp. physiol.
Psychol, 1964, 58, 344349.

DOWNIE, N.M., \& HEATH, R. W. Basic statistical methods. 2nd ed. New York: Harper \& Row, 1965.

FERSTER, C. B., \& SKINNER, B. F. Schedules of reinforcement. New York: Appleton-Century-Crofts, 1957.

HOFFMAN, H. S. The analysis of discriminated avoidance. In W. K. Honig (Ed.), Operant behavior: areas of research and application. New York: Appleton-Century-Crofts, 1966. Pp. 499-530.

HURWITZ, H. M. B. Method for discriminative avoidance-training. Science, 1964, 145, 1070-1071.

HURWITZ, H. M. B., \& DILLOW, P. V. The effect of constant current shock intensities on the acquisition of a discriminated avoidance response. Psychon. Sci, 1966, 5, 109-110.

PEARL, J., \& EDWARDS, R. E. Delayed avoidance conditioning: warning stimulus (CS) duration. Psychol Rep., 1962, 11, 375-380.

SIDMAN, M. Avoidance behavior. In W. K. Honig (Ed.), Operant behavior: areas of research and application. Appleton-Century-Crofts, 1966. Pp. $448-498$.

\section{Notes}

1. Animals and test apparatus were provided by Dr. W. C. Black, Purdue University, Department of Psychology. Grason-Stadler programming equipment was loaned to the author by Dr. V. H. Denenberg, Purdue University, Department of Psychology. The experiment was conducted while the author was at Purdue University. 